\title{
Prevalence of diaphragmatic muscle weakness and dyspnoea in Graves' disease and their reversibility with carbimazole therapy
}

Ravinder Goswami, Randeep Guleria ${ }^{1}$, Arun Kumar Gupta ${ }^{2}$, Nandita Gupta, Raman Kumar Marwaha, Jitender Nath Pande ${ }^{1}$ and Narayana Kochupillai

Departments of Endocrinology and Metabolism, ${ }^{1}$ Medicine and ${ }^{2}$ Radiodiagnosis, All India Institute of Medical Sciences, New Delhi 110029 , India

(Correspondence should be addressed to R Goswami; Email: gosravinder@hotmail.com or R Guleria; Email: randeepg@hotmail.com)

\begin{abstract}
Objectives: Dyspnoea is a common complaint among patients with thyrotoxicosis. However, its causative mechanisms have not been identified. We assessed the role of thoracic diaphragmatic muscle weakness in dyspnoea among patients with active Graves' disease.

Methods: Twenty-seven patients (19 female, 8 male) with active Graves' disease were assessed for the clinical severity of dyspnoea, functional (pressure generating capacity) and anatomical aspects (thickness and excursion) of the diaphragm at presentation. The severity of dyspnoea was assessed using a visual analogue scale (VAS) and the $6 \mathrm{~min}$ walk test. Lung function tests, diaphragmatic strength (sniff oesophageal pressure, SniffP $_{\text {oeso }}$ ), maximum inspiratory and expiratory pressures, diaphragmatic thickness and movements on real time ultrasonography were evaluated during normal and deep respiration. Twenty of the 27 patients were reassessed after achieving euthyroidism with carbimazole therapy at a mean interval of $5 \pm 2$ months.

Results: Reevaluation after carbimazole therapy revealed a significant reduction in dyspnoea on the VAS ( $59 \pm 26$ to $23 \pm 13 \%$ ). Patients covered a similar distance during the 6 min walk before and after euthyroidism. Significant improvement was observed in the vital capacity $(2.57 \pm 0.62$ to $2.94 \pm 0.60 \mathrm{l})$, forced expiratory volume in the first second $(2.21 \pm 0.49$ to $2.45 \pm 0.47 \mathrm{l})$, total lung capacity $(3.57 \pm 1.19$ to $4.1 \pm 1.12 \mathrm{l})$, diaphragmatic movement during deep respiration $(5.5 \pm 1.0$ to $6.6 \pm 1.1 \mathrm{~cm})$ and $\operatorname{SniffP}_{\text {oeso }}\left(68.7 \pm 23\right.$ to $\left.93.1 \pm 25.2 \mathrm{cmH}_{2} \mathrm{O}\right)$. There was no significant change in the distance walked in $6 \mathrm{~min}$, tidal volume, lung diffusion capacity and diaphragmatic thickness. There was no significant correlation between the net change in dyspnoea score and net change in lung function tests, diaphragmatic movement and SniffP ${ }_{\text {oeso. }}$.

Conclusions: Significant functional weakness of diaphragm muscle is present in patients with active Graves' disease. This weakness is more marked during a maximal respiratory manoeuvre, indicating a diminished diaphragmatic reserve which could be the cause of dyspnoea observed on exertion among patients with thyrotoxicosis.
\end{abstract}

European Journal of Endocrinology 147 299-303

\section{Introduction}

Dyspnoea is a common complaint (82\%) among patients with hyperthyroidism (1). The underlying patho-physiological mechanism remains unexplained, except when the patient has coexisting tracheal compression due to goiter or has cardiac failure. Studies assessing maximum inspiratory pressure (MIP) and expiratory pressure (MEP) at the mouth to evaluate respiratory muscle weakness in patients with thyrotoxicosis have given variable results possibly due to the wide variability in data obtained $(2,3)$. Currently, the most accurate and reproducible clinical assessment of diaphragm muscle strength and its movement is obtained by oesophageal pressure measurement during the sniff manoeuvre $\left(\right.$ SniffP $\left._{\text {oeso }}\right)$ and real time ultrasonography respectively $(4-7)$. The diaphragm is the main muscle for inspiration and accounts for twothirds of tidal volume. To our knowledge, there is no study where diaphragmatic muscle strength, movement and thickness have been assessed before and after treatment in patients with Graves' disease. We report results of our study in a cohort of patients with active Graves' disease demonstrating reduced diaphragm muscle strength at presentation and its normalisation following treatment.

\section{Materials and methods}

The subjects for the study included 27 consecutive patients with active Graves' disease (female 19, male 
8 , mean body mass index (BMI) $18.5 \pm 2.6 \mathrm{~kg} / \mathrm{m}^{2}$, age $30.1 \pm 10.9$ years) attending the Endocrine Clinic of All India Institute of Medical Sciences, New Delhi. Patients with thyroid crisis and those with febrile illness or cardiac problems were excluded. The distribution of age, sex and BMI corresponded to the usual pattern in such patients in our population (8-10). Thyrotoxicosis was diagnosed based on the criteria suggested by Volpe (11), i.e. Wayne's clinical score (12) for thyrotoxicosis $>19$, serum total tri-iodothyronine $\left(\mathrm{T}_{3}\right)$, thyroxine $\left(\mathrm{T}_{4}\right)$ and thyrotrophin (TSH) in the hyperthyroid range, a high $2 \mathrm{~h}$ and $24 \mathrm{~h}$ radioactive iodine uptake (normal range $2 \mathrm{~h}=5-15 \% ; 24 \mathrm{~h}=15-35 \%$ ) and diffuse thyromegaly. The mean duration of symptoms was 11.2 \pm 12.3 months. Wayne's clinical score for thyrotoxicosis, severity of dyspnoea, diaphragm muscle strength, its movement and thickness, lung function tests, serum $\mathrm{T}_{3}, \mathrm{~T}_{4}$ and TSH levels were assessed in all patients after obtaining informed consent. The patients were treated with carbimazole (10 mg t.i.d. doses). The average time taken to achieve euthyroidism was $7 \pm 2.2$ weeks. After achieving euthyroidism, carbimazole was continued at maintenance doses of $10-20 \mathrm{mg} /$ day. None of the patients received $\beta$-blockers. Patients were followed up at 1-monthly intervals and they continued to be euthyroid as indicated by a normal Wayne's clinical score for thyrotoxicosis $(<19)$ and normal circulating $\mathrm{T}_{3}$ and $\mathrm{T}_{4}$ levels. Of the 27 patients included in the study, 20 were reassessed after a mean follow-up interval of $5 \pm 2$ months for the severity of dyspnoea, diaphragmatic muscle strength and lung function tests.

SniffP $_{\text {oeso }}$ was used to assess diaphragmatic strength. A $10 \mathrm{~cm}$ long balloon catheter (PK Morgan Ltd., Rainham, Kent, UK) connected by a $100 \mathrm{~cm}$ long fine bore tubing to a Validyne differential pressure transducer $\left( \pm 150 \mathrm{cmH}_{2} \mathrm{O}\right)$ was used to record intraoesophageal pressure on a Grass polygraph (6). Oesophageal pressure at resting end expiration was used as the zero reference point. Patients were asked to perform ten sharp sniffs with a suitable rest period between the efforts to obtain reproducible readings. Visual feedback and encouragement was provided to the subjects to get the best response. The highest of the recorded pressures was used for analysis. The mean SniffP $_{\text {oeso }}$ values determined in our laboratory for 23 healthy

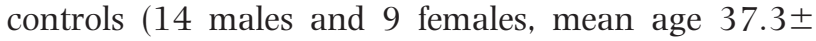
10.4 , range $20-52$ years) was $144 \pm 21.4 \mathrm{cmH}_{2} \mathrm{O}$. SniffP ${ }_{\text {oeso }}$ value $<101.8 \mathrm{~cm}$ (mean -2 s.D.) was considered as the subnormal (6). The MIP and MEP at the mouth (recorded from total lung capacity and residual volume respectively) were measured using a mercury manometer and converted into $\mathrm{cmH}_{2} \mathrm{O}$. The technique for recording the respiratory muscle pressure with this simple manometer has been validated in our laboratory and predication equations for normal subjects have been derived $(13,14)$.
Diaphragmatic excursions were measured in a supine position during tidal breathing and during vital capacity manoeuvres on the right and left sides by ultrasonography using a $3.5 \mathrm{MHz}$ sector transducer (Model ATL, HDI 3000, Philips Bothel, Washington, USA) $(5,7)$. A fixed skin position between the mid-clavicular and mid-axillary line was selected symmetrically to obtain a longitudinal plane of the hemidiaphragm (including the maximum renal bipolar length). A craniocaudal displacement line was placed at the depth of the midpoint of the kidney on expiration and the excursion on inspiration was measured along this line. The craniocaudal displacement of the diaphragm between the end-expiratory position and at the end-inspiratory position was measured to evaluate the movement of the diaphragm during tidal breathing. The same procedure was repeated to obtain a craniocaudal displacement of the diaphragm during the vital capacity manoeuvre. For each manoeuvre, at least three satisfactory readings were taken and the highest of the three readings was used for analysis. The thickness of the diaphragm was measured on ultrasound at functional residual capacity.

Spirometry (rolling seal electronic spirometer S232; P K Morgan) measurements included the respiratory rate, tidal volume, slow vital capacity, forced vital capacity, forced expiratory volume in the first second $\left(\mathrm{FEV}_{1}\right)$, maximum mid-expiratory flow rate $\left(\mathrm{PEF}_{25-75}\right)$ and peak expiratory flow rate (PEFR). Absolute lung volumes were measured using a constant volume whole body plethysmograph (P K Morgan). The procedure and the explanations given to the subjects were standardised as per the recommendations of the American Thoracic Society (15). The diffusion capacity was measured using the steady state technique. Breathlessness was assessed using the 6 min walk test followed by the oxygen cost diagram test (OCD) (16). Before carrying out the test, details of the procedure and the use of the OCD scale were carefully explained to the patients. In the 6 min walk test, the patient was asked to cover the maximum distance possible within a period of $6 \mathrm{~min}$ along a flat and straight corridor. The distance covered was recorded in metres. The patients were then asked to grade the severity of dyspnoea on an OCD scale. This is a visual analogue scale consisting of a line $100 \mathrm{~mm}$ in length with descriptive phrases at various points along the line indicating the oxygen requirements for different activities. The upper end of the line indicates 'no breathlessness' while the lower end corresponds to 'maximum breathlessness'. The patients were asked to mark the point on this scale where they became breathless. The distance from the top of the scale to the mark put by the patient was measured in millimetres and this was used as an index of the severity of dyspnoea.

Estimation of circulating total $\mathrm{T}_{3}$ and $\mathrm{T}_{4}$ levels was done by an in-house RIA using ${ }^{125}$ I-labelled $\mathrm{T}_{3}$ and $\mathrm{T}_{4}$ prepared and purified in our laboratory adopting 
the modified chloramine-T technique $(17,18)$. The inter- and intra-assay variations ranged from 6 to $8 \%$ respectively. Serum TSH was estimated by an IRMA assay using a commercial kit (Medicorp Inc., 5800 Royalmount, Montreal, Quebec, Canada). The normal range for $\mathrm{T}_{4}, \mathrm{~T}_{3}$ and $\mathrm{TSH}$ were $51-154 \mathrm{nmol} / \mathrm{l}$, $1.1-2.9 \mathrm{nmol} / \mathrm{l}$ and $0.3-4 \mathrm{mU} / \mathrm{l}$ respectively.

\section{Analysis}

Data are presented as means \pm S.D. The paired $t$-test was used to assess the significance of the difference in the means of the SniffP ${ }_{\text {oeso, diaphragm excursion and }}$ thickness, lung function tests, dyspnoea index on the OCD test and 6 min walk test before and after carbimazole therapy. Variables not normally distributed (serum $\mathrm{T}_{4}$, TSH, dyspnoea index, MEP and MIP) were log transformed and then subjected to a paired $t$-test. However, data shown in Table 1 are in the non-transformed form. Pearson's correlation coefficient was used to assess correlation among the above parameters in the hyperthyroid state in the 27 patients recruited for the study.

\section{Results}

Twenty-four of the 27 patients with Graves' disease had dyspnoea $(88.8 \%)$. Table 1 gives the clinical characteristics of the patients, severity of dyspnoea, diaphragm function indices and lung function tests at the time of presentation for all the 27 patients with Graves' disease and the data obtained on follow-up with carbimazole therapy in 20 of them. The mean BMI and serum total $\mathrm{T}_{3}$ and $\mathrm{T}_{4}$ improved significantly after treatment and on follow-up all the patients had become clinically and biochemically euthyroid. There was a significant improvement in the subjective assessment of breathlessness on the OCD scale after treatment. However, this was not accompanied by significant improvement in the distance covered during the 6 min walk test.

The strength of the diaphragmatic muscle contraction, as measured by SniffP $_{\text {oeso }}$ was below normal in 26 of 27 patients $(96.2 \%)$ at presentation. It improved with carbimazole therapy in all the 20 patients at $5 \pm 2$ months of follow-up (Fig. 1). Only nine $(45 \%)$ of them had subnormal values posttreatment (pre- vs post-treatment, $P<0.01$ ). There was a significant improvement in the mean SniffP $_{\text {oeso }}$ value $(P<0.0001)$. On ultrasonography, a significant increase in the excursion of the diaphragm on deep respiration (vital capacity manoeuvre) was observed after treatment. However, the mean diaphragmatic excursion during the normal respiration (tidal volume manoeuvre) and diaphragm muscle thickness did not differ significantly before and after carbimazole therapy (Table 1).

Lung function tests in the untreated thyrotoxic state showed a diminished mean absolute vital capacity, which was $75.9 \%$ of the predicted value using the equation-prediction norms in our laboratory. Following treatment it increased significantly and reached up to

Table 1 Basal data (means \pm S.D.) of 27 patients with thyrotoxicosis and comparison of pre- and post-treatment values $(n=20)$.

\begin{tabular}{|c|c|c|c|c|}
\hline \multirow[b]{2}{*}{ Parameters } & \multirow[b]{2}{*}{ All patients $(n=27)$} & \multicolumn{2}{|c|}{$\begin{array}{l}\text { Pre- and post-treatment data in } \\
\text { patients who came for follow-up } \\
\qquad(n=20)\end{array}$} & \multirow[b]{2}{*}{$P$} \\
\hline & & Pre-treatment & Post-treatment & \\
\hline Age (years) & $30.1 \pm 10.9$ & $26.6 \pm 9.1$ & - & - \\
\hline Female:male & $19: 8$ & 15:5 & - & - \\
\hline $\mathrm{BMI}\left(\mathrm{kg} / \mathrm{m}^{2}\right)$ & $18.5 \pm 2.6$ & $19.2 \pm 2.6$ & $21.8 \pm 2.6$ & $<0.0001$ \\
\hline Pulse rate (per min) & $106 \pm 8$ & $104 \pm 8$ & $85 \pm 6$ & $<0.001$ \\
\hline Serum total $\mathrm{T}_{3}(\mathrm{nmol} / \mathrm{l})$ & $8.6 \pm 3.1$ & $9.1 \pm 3.1$ & $2.6 \pm 1.2$ & $<0.0001$ \\
\hline Serum total $\mathrm{T}_{4}(\mathrm{nmol} / \mathrm{l})$ & $277.9 \pm 87.5$ & $287.0 \pm 93.9$ & $84.4 \pm 38.6$ & $<0.001$ \\
\hline Serum TSH $(\mathrm{mU} / \mathrm{l})$ & $0.05 \pm 0.05$ & $0.05 \pm 0.06$ & $0.99 \pm 1.9$ & 0.13 \\
\hline Dyspnoea index (\%) & $56.6 \pm 27.9$ & $59.0 \pm 26.0$ & $23.0 \pm 13.0$ & $<0.0001$ \\
\hline Distance covered in $6 \mathrm{~min}$ OCD test $(\mathrm{m})$ & $551.3 \pm 63.5$ & $549.2 \pm 62.1$ & $552.7 \pm 62.1$ & 0.83 \\
\hline Diaphragm movement in normal respiration $(\mathrm{cm})$ & $2.0 \pm 0.4$ & $2.0 \pm 0.4$ & $1.8 \pm 0.2$ & 0.14 \\
\hline Diaphragm movement in deep respiration $(\mathrm{cm})$ & $5.4 \pm 0.2$ & $5.5 \pm 1.1$ & $6.6 \pm 1.1$ & $<0.01$ \\
\hline Diaphragm thickness (mm) & $2.0 \pm 0.4$ & $2.0 \pm 0.5$ & $2.0 \pm 0.3$ & 0.42 \\
\hline Vital capacity (I) & $2.6 \pm 0.7$ & $2.6 \pm 0.6$ & $2.9 \pm 0.6$ & $<0.0001$ \\
\hline $\mathrm{FEV}_{1}(\mathrm{I})$ & $2.2 \pm 0.6$ & $2.2 \pm 0.5$ & $2.4 \pm 0.5$ & $<0.01$ \\
\hline $\mathrm{FEF}_{25-75}(\mathrm{l} / \mathrm{s})$ & $2.7 \pm 1.0$ & $2.6 \pm 0.9$ & $2.7 \pm 0.8$ & 0.75 \\
\hline Residual volume (I) & $1.1 \pm 0.6$ & $1.1 \pm 0.7$ & $1.1 \pm 0.5$ & 0.92 \\
\hline Total lung capacity (I) & $3.6 \pm 0.2$ & $3.6 \pm 1.2$ & $4.1 \pm 1.1$ & 0.01 \\
\hline Respiratory rate (per min) & $27 \pm 5$ & $27 \pm 5$ & $23 \pm 4$ & 0.02 \\
\hline $\operatorname{MEP}\left(\mathrm{cmH}_{2} \mathrm{O}\right)$ & $69.0 \pm 25.1$ & $72.6 \pm 18.4$ & $92.4 \pm 35.6$ & 0.11 \\
\hline $\operatorname{MIP}\left(\mathrm{cmH}_{2} \mathrm{O}\right)$ & $70.3 \pm 19.8$ & $68.6 \pm 17.1$ & $80.6 \pm 30.3$ & 0.16 \\
\hline SniffP ${ }_{\text {oeso }}\left(\mathrm{cmH}_{2} \mathrm{O}\right)$ & $66.0 \pm 22.7$ & $68.7 \pm 23.1$ & $93.1 \pm 25.2$ & $<0.0001$ \\
\hline
\end{tabular}


(a)

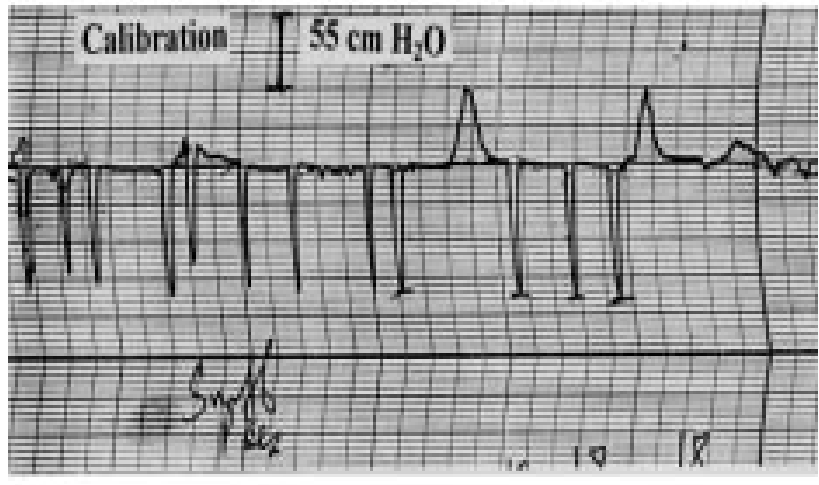

(b)

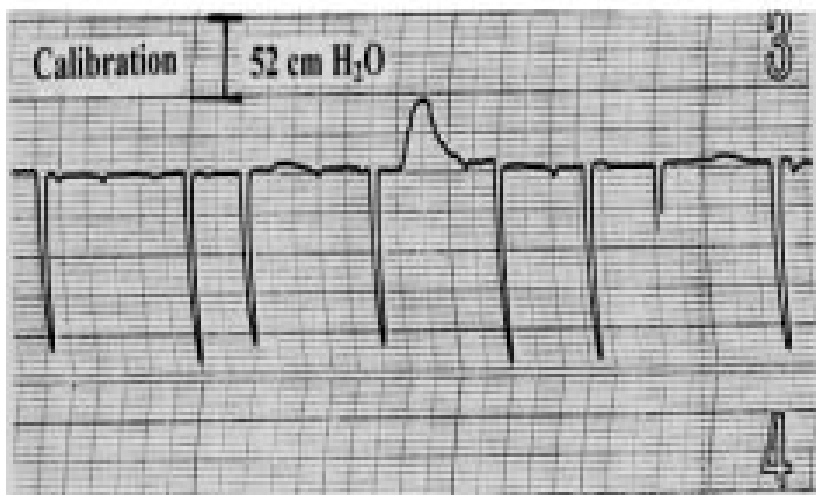

Figure $1 \mathrm{SniffP}_{\text {oeso }}$ tracing in a patient with Graves' disease (a) before $\left(71 \mathrm{cmH}_{2} \mathrm{O}\right)$ and (b) after carbimazole therapy (115 $\left.\mathrm{cmH}_{2} \mathrm{O}\right)$.

$89.9 \%$ of the predicted norms $(P<0.0001)$. The absolute and predicted mean values for the total lung capacity, $\mathrm{FEV}_{1}$ and PEFR also improved significantly after the patients became euthyroid (Table 1) and the respiratory rate showed a significant decline $(P<0.05)$.

The MIP and MEP measured at the mouth before treatment were lower than the values predicted for our laboratory. Although these pressures increased after treatment, the difference did not attain statistical significance. The tidal and residual volumes as well as the diffusion capacity were within the normal limits before treatment and showed no significant change after carbimazole therapy (Table 1).

When all the 27 patients were analysed as a group, there was a significant correlation between the dyspnoea index and diaphragm excursion during normal respiration $(P<0.001)$. However, no significant correlation was observed between the dyspnoea index $(6 \mathrm{~min}$ walk and OCD tests) and the severity of thyrotoxicosis (as evaluated by Wayne's score and circulating total $\mathrm{T}_{3}$ and $\mathrm{T}_{4}$ levels), the SniffP $\mathrm{P}_{\text {oeso, }}$ diaphragmatic thickness and its excursions, and the lung function tests.

\section{Discussion}

In the present study $88.8 \%$ of patients with active Graves' disease had dyspnoea. The various factors which could lead to the high prevalence of dyspnoea in patients with thyrotoxicosis include an increased ventilatory drive, airway resistance, diminished lung compliance and respiratory muscle weakness (1). In an earlier study, we had observed a significant improvement in dyspnoea, vital capacity and MIP and MEP measured at the mouth following carbimazole therapy in patients with active Graves' disease (19). Similar observation has been made by other investigators when MIP and MEP at the mouth were used to assess respiratory muscle strength in patients with thyrotoxicosis $(2,3,20)$.

In the present study, subnormal pressures were observed in the thyrotoxic state when SniffP ${ }_{\text {oeso }}$ was used as an index of global inspiratory muscle and thoracic diaphragm strength (Fig. 1). This observation together with the significant improvement and even reversion of SniffP $\mathrm{P}_{\text {oeso }}$ to normal following treatment indicated the presence of respiratory muscle weakness in patients with thyrotoxicosis. A significant improvement in vital capacity and an increase in the maximum inspiratory and expiratory muscle pressures also indicated respiratory muscle weakness in them. The above changes were not associated with significant change in the tidal volume. These observations collectively indicated that respiratory muscle weakness may manifest in patients with thyrotoxicosis during excessive physical effort and increased oxygen demand. A significant increase in diaphragmatic muscle excursion on deep respiration after carbimazole therapy, but absence of similar change on normal respiratory effort, also supports the above observation.

Meir et al. (20) measured SniffP ${ }_{\text {oeso }}$ in four patients with thyrotoxicosis and found it to be on the lower limit of the normal range in three of them and below normal in one patient. SniffP ${ }_{\text {oeso }}$ improved in all of them after they became euthyroid. However, since only four patients were included in this study, it was not possible to draw any conclusion about the diaphragmatic weakness (20). McElvaney et al. (3) reported reduced MIP and MEP and the presence of respiratory muscle weakness in patients with thyrotoxicosis, but could not correlate it with their dyspnoea intensity score. In the present study we could not demonstrate any correlation among the physiological parameters measured by the lung function tests, excursion of the diaphragm on deep respiration and SniffP $_{\text {oeso }}$ pressures. This lack of correlation could be because the onset of the disease is insidious and the patients may slowly adapt to the symptom of dyspnoea. Alternatively, such a lack of correlation could be due to the fact that the perception of dyspnoea involves a combination of physiological and psychological factors. In the present study we did not assess the role of 
psychological factors which could be contributing to the dyspnoea in patients with thyrotoxicosis.

The mechanism by which the respiratory muscle strength is improved once patients become euthyroid is not known. Significant improvement in the vital capacity following attainment of euthyroidism may apparently seem to contribute to the improvement in MEP due to the length tension properties of the respiratory muscles. However, there was no change in the residual volume and therefore it is likely that a true increase in the strength of the inspiratory muscle has occurred. Recently, Norrelund et al. (21) assessed muscle mass of the thigh by computerised tomography and body composition in patients with thyrotoxicosis. A decrease in BMI and 20\% reduction in skeletal muscle mass were observed during thyrotoxicosis, which reversed after 9 months of carbimazole therapy (21). In the present study, although there was a significant increase in BMI following a mean interval of 5 months of carbimazole therapy, this was not accompanied by an increase in the diaphragm muscle thickness. A shorter duration of follow-up, i.e. 5 months instead of 9 months, and limited sensitivity of the ultrasonography with a $3.5 \mathrm{MHz}$ transducer may be the reasons for the non-documentation of an increase in the thoracic diaphragm muscle thickness in our study.

In an earlier study, we have described dyssynergia of the detrusor muscle as the cause of urinary bladder dysfunction in patients with thyrotoxicosis, which reversed on treatment (8). It is possible that dyssynergia of the thoracic diaphragm muscle might have contributed to poor diaphragmatic muscle pressure and its movement during deep respiration. Electromyography studies of the thoracic muscle diaphragm in patients with thyrotoxicosis may reveal such changes.

Thus, the present study reveals that patients with active Graves' disease have significant functional weakness of diaphragm muscle. This weakness is more marked during maximal respiratory manoeuvre, indicating a diminished diaphragmatic reserve which could cause the dyspnoea on exertion among patients with thyrotoxicosis.

\section{References}

1 Ingbar DH. The respiratory systems in thyrotoxicosis. In Werner and Ingbar's The Thyroid - a Fundamental and Clinical Textbook, edn. 5, pp 744-758. Eds LE Braverman \& RD Utiger. Philadelphia, PA: Lippincott, 1991.

2 Siafakas NM, Milona I, Salesiotou V, Filaditaki V, Tzanakis N \& Bouros D. Respiratory muscle strength in hyperthyroidism before and after treatment. American Review of Respiratory Disease $19921461025-1029$.

3 McElvaney GN, Wilcox PG, Fairbarn MS, Hilliam C, Wilins GE, Pare PD et al. Respiratory muscle weakness and dyspnoea in thyrotoxic patients. American Review of Respiratory Disease 1990 $1411221-1227$.

4 Miller JM, Moxham J \& Green M. The maximal sniff in the assessment of diaphragm function in man. Clinical Science 1985 $6991-96$.

5 Houston JG, Morris AD, Howie CA, Reid JL \& McMillan N. Technical report: quantitative assessment of normal hemidiaphragmatic movements - a reproducible method using ultrasound. Clinical Radiology $1992 \mathbf{4 6} 405-407$.

6 Arora N, Guleria R, Pande JN \& Sharma SK. Comparison of sniff nasal inspiratory pressure and mouth inspiratory pressure for evaluation of respiratory muscle strength in COAD, ILD and normal subjects. American Journal of Respiratory and Critical Care Medicine 2001163 (Suppl) 156.

7 Narayanan R, Guleria R, Gupta AK \& Pande JN. Ultrasound assessment of diaphragmatic movements and its correlation with lung function in patients with chronic obstructive airway disease. Chest 2000118 (Suppl) 201.

8 Goswami R, Seth A, Goswami AK \& Kochupillai N. Prevalence of enuresis and other bladder symptoms in patients with active Graves' disease. British Journal of Urology 199780 563-566.

9 Goswami R, Jayasuryan N, Jaleel A, Tandon N \& Kochupillai N. Insulin autoantibodies before and after carbimazole therapy in Asian Indian patients with Graves' disease. Diabetes Research and Clinical Practice 199840 201-206.

10 Kochupillai N \& Goswami R. Unique clinical features of thyrotoxicosis as seen in India. Journal of the Association of the Physicians of India $2000 \mathbf{4 8}$ (Suppl) 53-66.

11 Volpe A. Graves' disease. In Werner and Ingbar's The thyroid - a Fundamental and Clinical Textbook, edn. 5, pp 887-916. Eds LE Braverman \& RD Utiger. Philadelphia, PA: Lippincott, 1991.

12 Crooks J, Murray IPC \& Wayne EJ. Statistical methods applied to the clinical diagnosis of thyrotoxicosis. Quarterly Journal of Medicine 195928 211-234.

13 Guleria R \& Jindal SK. Normal maximal expiratory and inspiratory pressures in healthy teenagers. Journal of the Association of Physicians of India $1992 \mathbf{4 0} 108-109$.

14 Pande JN, Verma SK, Singh SP, Guleria R \& Khilani GC. Respiratory pressures in normal Indian subjects. Indian Journal of Chest Diseases and Allied Sciences $1998 \mathbf{4 0} 251-256$.

15 ATS Statement, Snowbird workshop on standardization of spirometry. American Review of Respiratory Disease 1979119 $831-838$.

16 Mahler DA \& Wells CK. Evaluation of clinical methods for rating dyspnoea. Chest 198893 580-586.

17 Bolton AE \& Hunter WM. The labelling of proteins to high specific radioactivities by conjugation to a ${ }^{125}$ I-containing acylating agent. Biochemical Journal 1973133 529-538.

18 Kochupillai N \& Yalow RS. Preparation, purification and stability of high specific activities ${ }^{125}$-I labeled thyronines. Endocrinology $1978102128-135$.

19 Guleria R, Goswami R, Shah P, Pande JN \& Kochupillai N. Dyspnoea, lung function and respiratory muscle pressures in patients with Graves' disease. Indian Journal of Medical Research 1996104 299-303.

20 Mier A, Brophy C, Wass JA, Besser GM \& Green M. Reversible respiratory muscle weakness in hyperthyroidism. American Review of Respiratory Disease 1989139 529-533.

21 Norrelund H, Hove KY, Brems-Dalgaard E, Jurik AG, Nielsen LP, Nielsen $\mathrm{S}$ et al. Muscle mass and function in thyrotoxic patients before and during medical treatment. Clinical Endocrinology $199951693-699$.

Received 22 January 2002

Accepted 12 June 2002 